\title{
Rehabilitation of existing building structure in expansive soils: A case study in Laghouat, Algeria
}

\author{
Ouai A
}

\author{
Engineer in National Organization for the Technical Control of Construction (CTC-Sud), Laghouat Algeria. \\ * Corresponding Author: ouai_aissa@yahoo.fr
}

Received: 14-09-2016 $\quad \underline{\text { Revised: 09-07-2017 }}$ Accepted: 12-07-2017

\begin{abstract}
This work presents results obtained from a case study conducted on M'kam neighborhood (600 housing social city) in Laghouat, Algeria. The bloc (J) in this location, suffering from damages that are attributed to the expansive clayey soil interaction with sewage disposal under foundations was the subject of rehabilitation in this study.

The principal causes of observed structural damages were studied through diagnostic expertise (inspection-evaluation process) of the cracks and sewage disposal system of bloc (J). The results of this diagnostic investigation show that the main damages were mainly due to swelling of soil in presence of losses from sewage disposal. Remedial actions were suggested to revise and repair all the sewage disposal system and strengthen the foundations of the building to avoid further damages.
\end{abstract}

Key words: Expansive soils, Sewage disposal system, Damage, Rehabilitation, Repairing.

\section{Introduction}

Expansive soils can exert, in presence of water, enough force on a building to cause severe damages. Cracked foundations, floors, and basement walls are typical types of this damage. The occurrence of expansive soils in more pronounced in southern and arid regions such as the case of region of Laghouat in south Algeria (Kamel et al., 2013; Seco et al., 2011). Due to important swelling and shrinkage potential of soils in arid region, it has become a severe problem to civil engineers. When a construction is realized on expansive soil under arid environmental conditions without the pre-understanding of their properties, the damage will be dramatically severe (Kolay and Ramesh, 2016).

This paper presents a case study from an arid region (Laghouat, Algeria) characterized by a surficial formation of highly expansive soil. A social housing building (Bloc J) with signs of distress and observable cracks was investigated to report the source and level of damages and propose rehabilitation measures.

\section{State of the studied site}

The studied site is located in Wilaya of Laghouat, Algeria (Figure 1). Laghouat is considered a semi-arid region, characterized by a hot dry climate in summer, followed by a cold rainy season. The studied site (M'kam city) is covered by an expansive clayey soil. The structure of studied bloc $(\mathrm{J})$ is realized with reinforced concrete.

The bloc (J) consists of sanitary basement, ground commercial floor and three floors for residential use as shown in Figure 2. The visual inspection of the structure revealed evidence of cracking of external and internal walls of first and second floors. Some photographs showing the current state of cracks inside and outside bloc (J) building are presented in Figure 3. Most of the cracks in the building were found to be at the internal walls of first and second floors. 


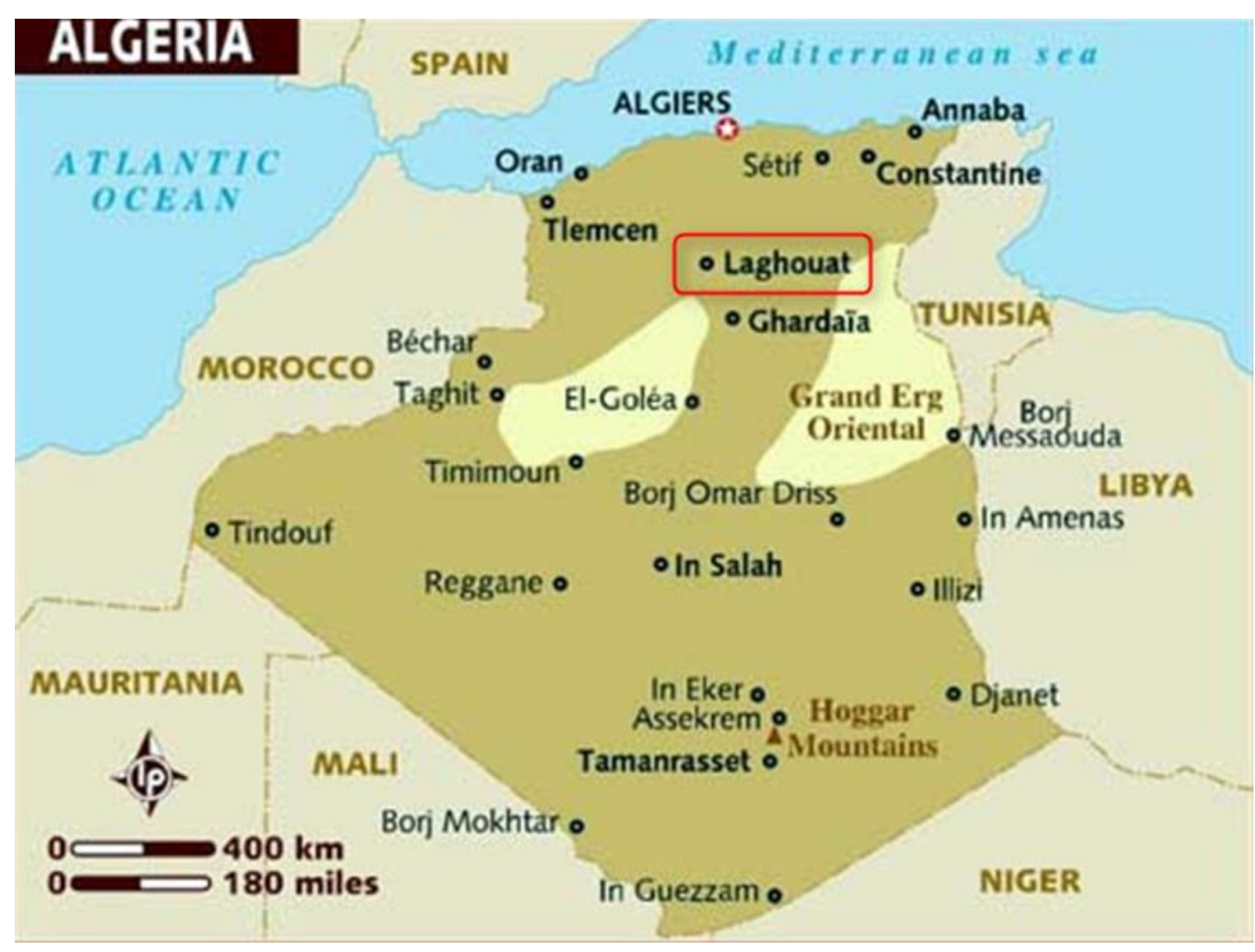

Fig 1. . Map of Algeria, situation of Laghouat.

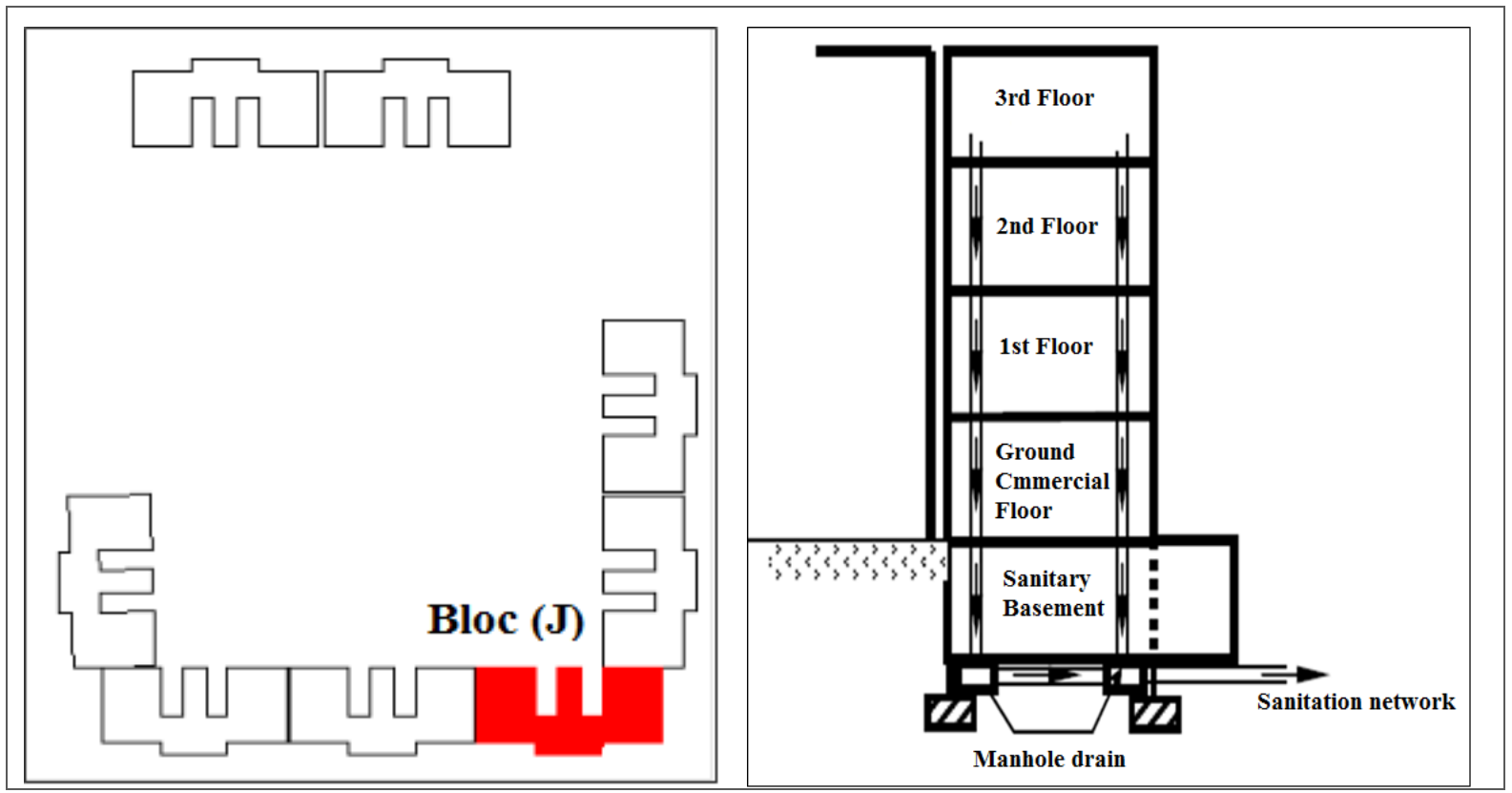

Fig 2. Situation and general structure of Bloc (J) building. 


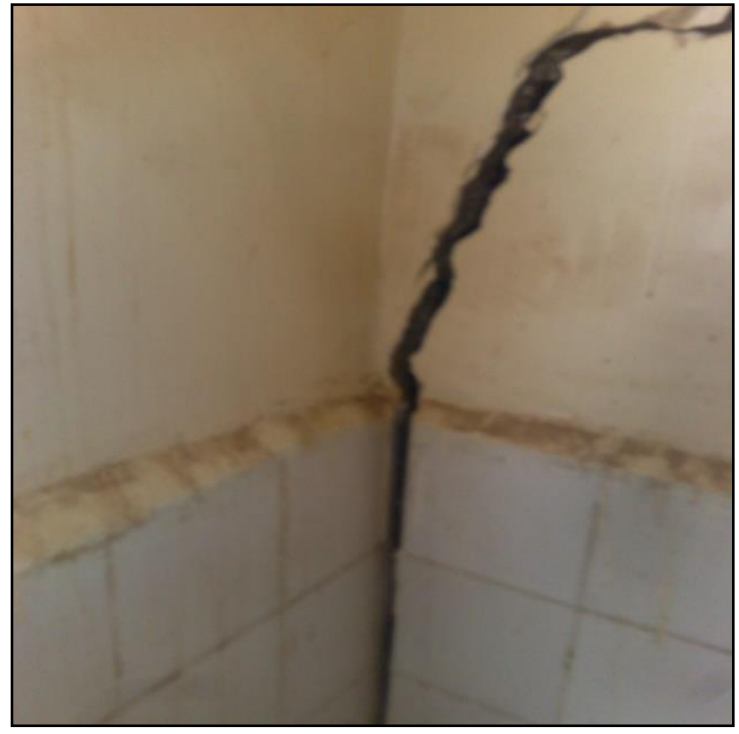

a) Inside

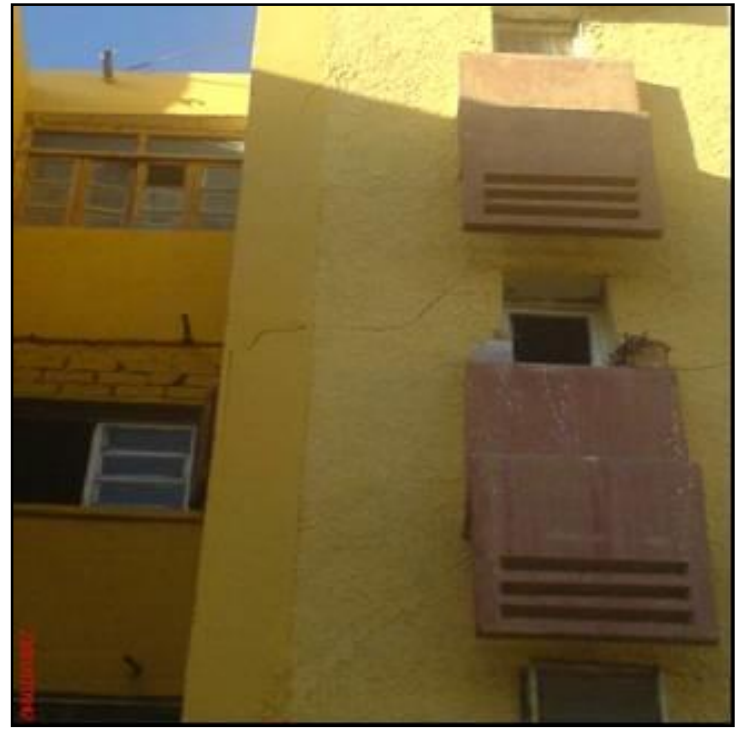

b) Outside

Fig 3. State of cracks inside and outside bloc (J) building.

\section{Foundation and building sewer inspection}

The foundation of the studied building is of the superficial type, it is formed of insulated soles bonded by stringers. These soles are placed on a massive concrete. The foundation plan of the studied building is presented in Figure 4.

The main sanitary sewer system of the building is located in the basement and collects wastewater from the floors sewers. Blockages in the building sewer can cause backups of sewage toilets, showers and floor drains. These types of blockages are sometimes referred to as basement backups, which can lead to disease, destruction of valuables and damage of building property. Damages in the building sewers system have been located in the basement of the studied building, which causes infiltration of wastewater through cracked pipes (Figure 5).

\section{Repair and remedial measures}

The type of any proposed repair or remedial measures undertaken on a damaged building depend on the following factors: the extent of the damage, the source causing the damage and the cost of remedial solutions (Mughieda and Hazirbaba, 2015). In this study the following remedial measures and building repair types were recommended:

\subsection{Building sewer repair}

The first step to repair the damages is repairing building sewers. The solution consist on performing an inspection of wastewater utility, prior any repair, to identify if there is a problem in floors sanitary sewer pipe system. After this preliminary inspection, the main sewer manhole located in the interior of building (in basement) is changed to the exterior, before the main sanitary sewer in the street, to avoid any wastewater infiltrations around the foundations (Figure 6). 


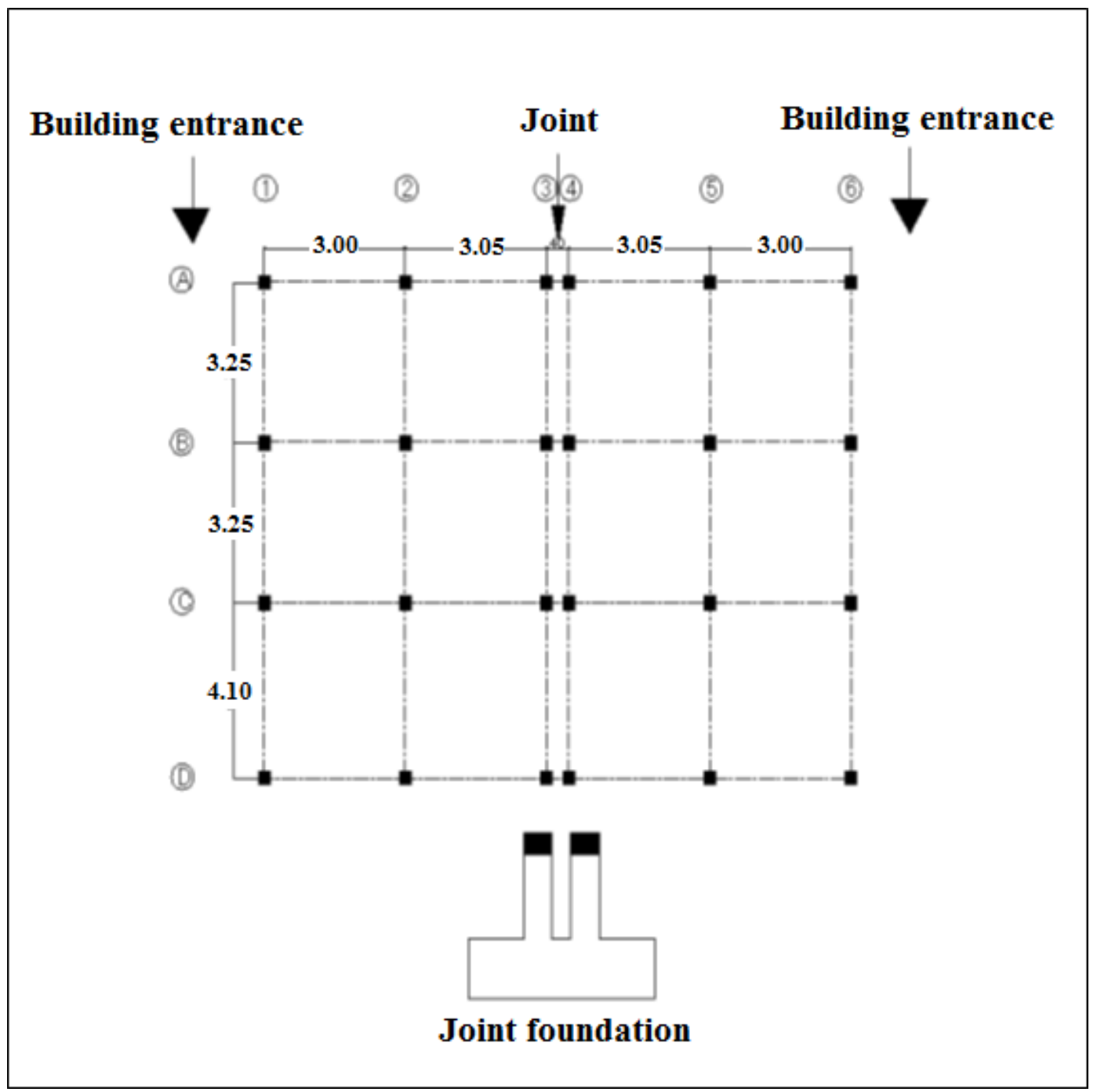

Fig 4. Foundation plan of the building.
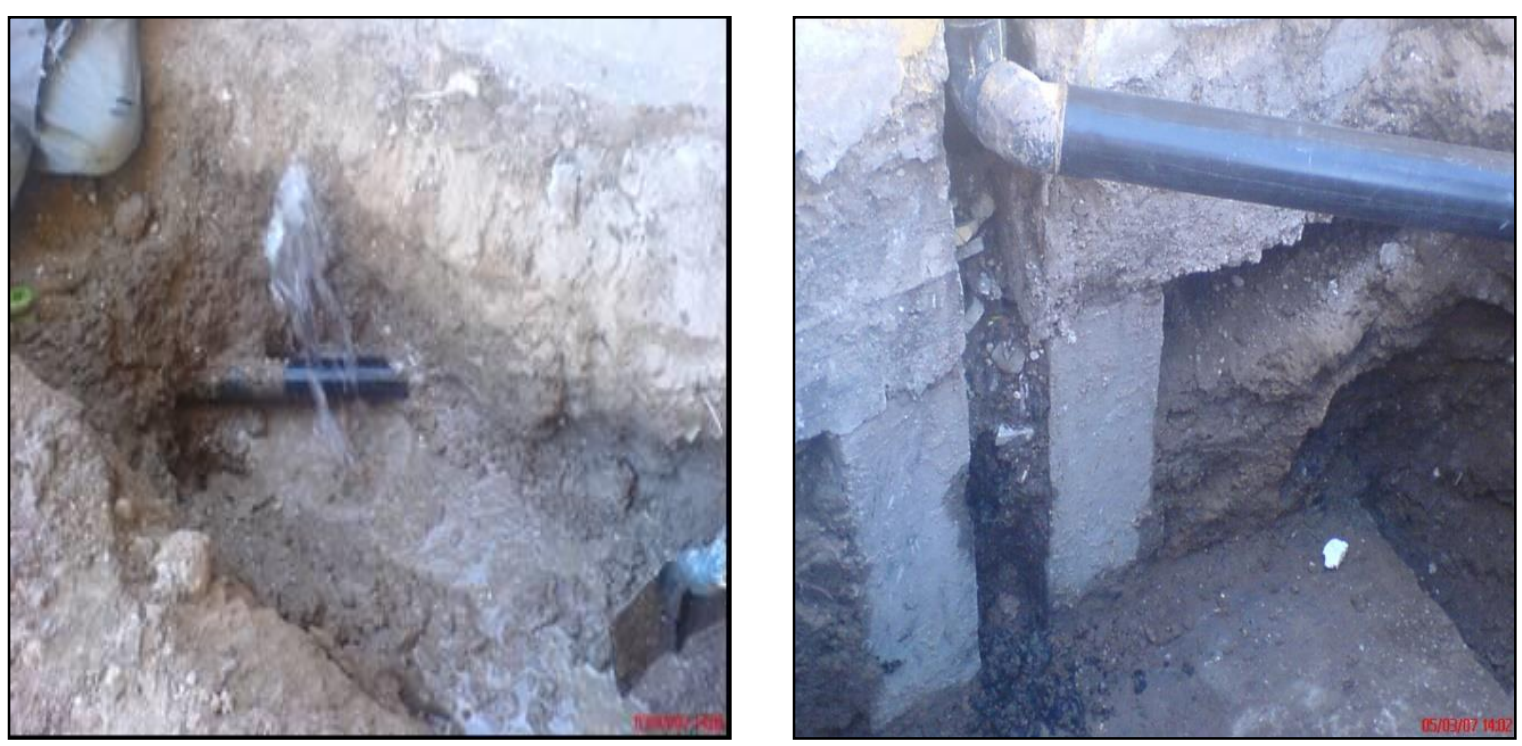

Fig 5. Infiltration of wastewater through cracked pipes. 

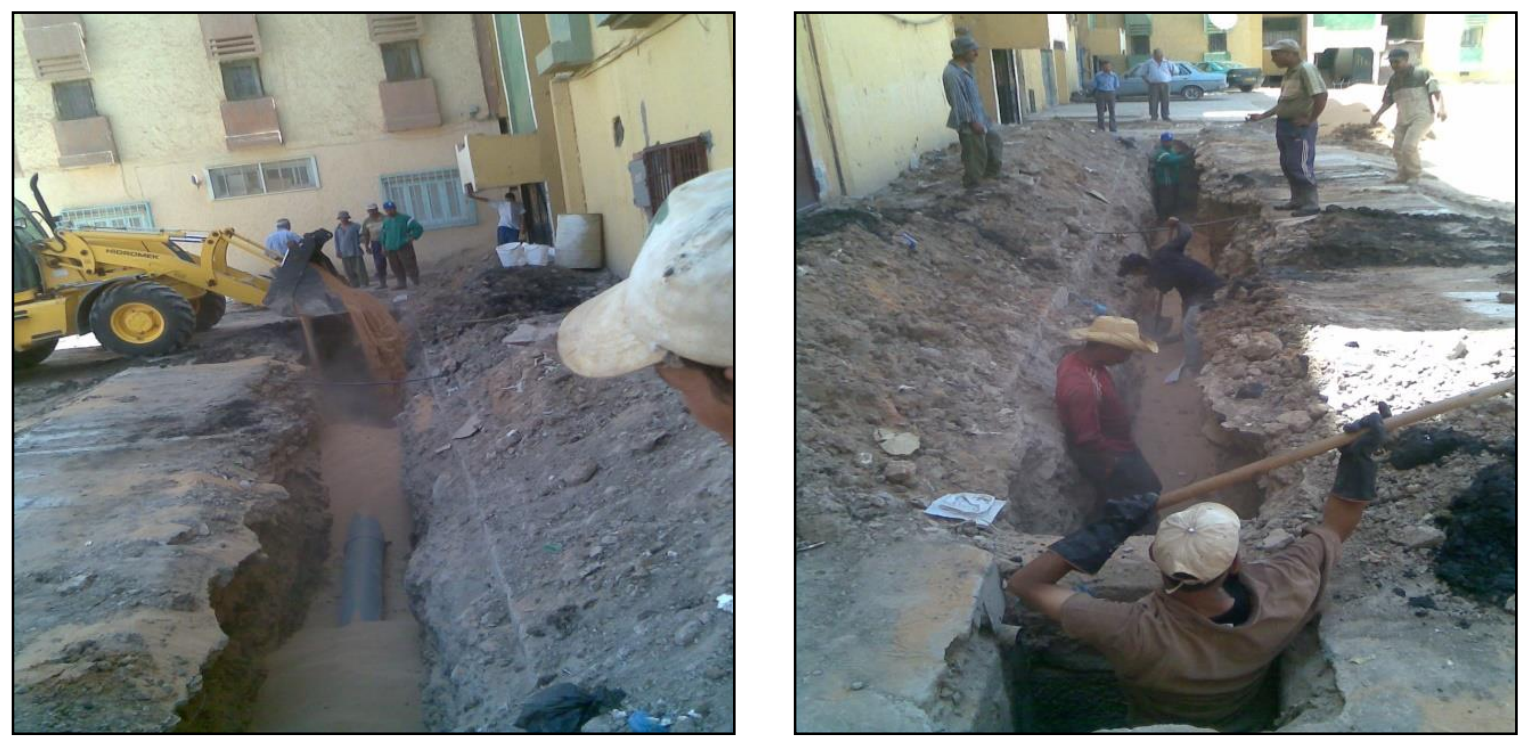

Fig 6. Main manhole sewers were moved completely outside the building.

\subsection{Building foundations reinforcement}

It is inspected that repairing wastewater utility and elimination of any infiltration of wastewater to the foundations specified in previous section, will restrict the problem of swelling and shrinkage of the foundation soil appreciably. If no further movement is detected after the implementing of the remedial measures of building sewers, foundations and crack repair may proceed.

Inspection and evaluation are the principal phase of any rehabilitation and repair of the building. Inspection of the building is the process by which any damage in the building foundations is observed and recorded, while evaluation refers to all works to determine and assess the condition of the building based on the inspection step. It is intended to evaluate the general condition of the structure and identify any areas of deficiency. The followed repair work is largely based on the conclusions of the process of inspection and evaluation.
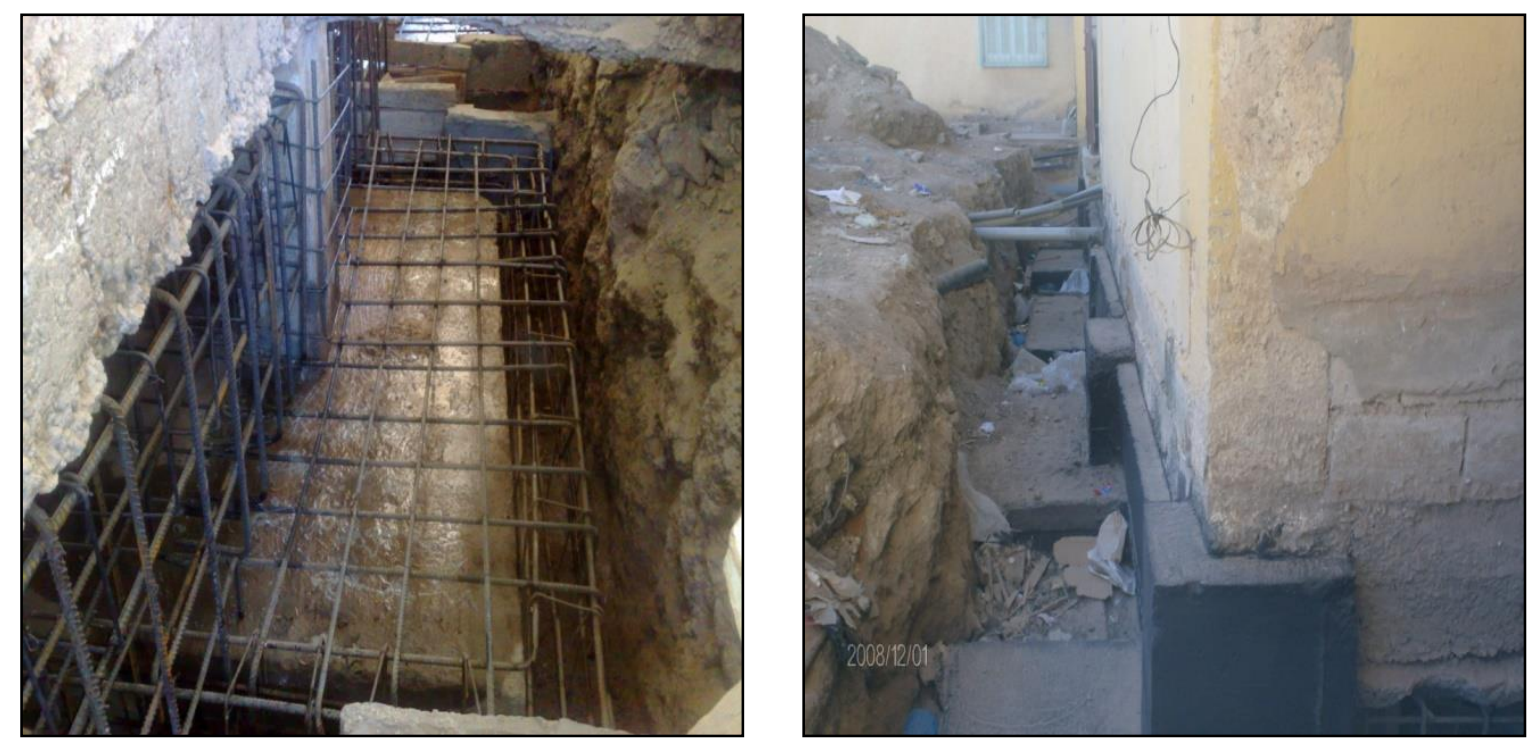

Fig 7.

Repairing of a concrete structure such as foundations means to replace, correct or strengthen damaged, faulty materials; components structure (Idrissou, 2006). In order to improve the 
stability of the building and to correct the expansion joint openings caused by the differential movement of the foundations, reinforced concrete footings with peripheral sails were installed on both sides of each expansion joint along the total building basement height (Figure 7).

\section{Conclusions}

A damaged social housing building due to an expansive soil was investigated in the form of a case study. Diagnostic analyses of the damage were conducted through inspection and evaluation process. This finding of the followed process was significant in identifying the causes of differential movement of foundation and eventual cracking of the interior and exterior walls of the building.

Remedial measures were prescribed in the current study. The proposed remedial measures focused on revising and repairing the wastewater system of all floors and moving the main sewer manhole to the exterior of building to avoid any infiltration and isolate the foundations of the building from the wastewater so.

We propose also a reinforcement of the foundations, to enhance the stability of the building and to rectify the openings at the expansion joints caused by the differential movement of the foundations, by using a reinforced concrete footings with peripheral sails were installed at both sides of each expansion joint along the total height of the building basement.

\section{References}

Idrissou, M. M. (2006). Reliability in interpreting non-destructive testing (NDT) results of concrete structures (Doctoral dissertation, Universiti Teknologi Malaysia).

Kamel, G. M., Idriss, G., \& Benchaa, B. (2013). Effet de chaux, ciment et sel sur le potentiel de gonflement des argiles gonflantes des régions arides en Algérie. European Journal of Environmental and Civil Engineering, 17(5), 315-328.

Kolay, P. K., \& Ramesh, K. C. (2016). Reduction of expansive index, swelling and compression behavior of kaolinite and bentonite clay with sand and class C fly ash. Geotechnical and Geological Engineering, 1(34), 87-101.

Mughieda, O., \& Hazirbaba, K (2015). Expansive Clay Soil-Structure Interaction: A Case Study. In: Recent Advances in Mechanics, Mechatronics and Civil, Chemical and Industrial Engineering, Proceedings of the International Conference on Civil Engineering. ISBN: 978-1-61804-325-2, pp: 195-200.

Seco, A., Ramírez, F., Miqueleiz, L., \& García, B. (2011). Stabilization of expansive soils for use in construction. Applied Clay Science, 51(3), 348-352. 